\title{
Creativity in medical education: concepts related to creative capacity
}

\author{
Yura Kim, Young Hwan Lee \\ Department of Medical Humanities, Yeungnam University College of Medicine, Daegu, Korea
}

Received: December 12, 2019

Revised: February 24, 2020

Accepted: March 2, 2020

Corresponding author:

Young Hwan Lee

Department of Medical Humanities,

Yeungnam University College of

Medicine, 170 Hyeonchung-ro,

Nam-gu, Daegu 42415, Korea

Tel: +82-53-640-6999

Fax: +82-53-629-2252

E-mail:yhlee3535@ynu.ac.kr
In the 21st-century postmodernism era, which represents diversity and relativity, one of the most essential elements in the field of education is to strengthen individual human values. Accordingly, we must focus on developing capacity in order to adapt to change. It is clear that the medical field maximizes the need for new judgments to solve life-related problems constantly, and this problem-solving capacity is an essential skill for a physician. Problem-solving capacity can be achieved simultaneously with creativity to apply them in an appropriate manner based on standardized expertise and well-trained skills. Creativity is also a key element that medical education is currently pursuing. Many studies on creativity have resulted in confusion and misunderstandings on the concept of creativity due to similar terms and varied definitions, such as creation, innovation, etc. In this study, we attempt to identify the importance of creativity in medical education by comparing and organizing concepts related to creative capacity.

Keywords: Creative thinking; Creativity; Medical education; Problem-solving

\section{Introduction}

Medical education is a field where the coldest reason meets the hottest emotion, reality and context are more intertwined than in any other discipline, and it requires constant attention to those who suffer sober judgment and patient care [1]. These efforts have steadily evolved since the inception of medical education in the University of Bologna (Università di Bologna, 1088) and the University of Salerno (Università degli Studi di Salerno, 1231).

Modern medical education has undergone many innovative changes since the commencement of systematic medical education in 1910 under the "Flexner Report." Professor Harden of Dundee University presented the "SPICES" model, outlining innovative educational strategies against traditional methods (Table 1) [2]. He believes that innovative education should change from "teacher-centered" to "student-centered," and learning requires a shift from "information-gathering" to "problem-based," and also from "hospi- tal-based" to "community-based." The model also states that the curriculum should change from "discipline-based" to "integrated/ inter-professional," from "uniform standard program" to "elective with a core program" and a pre-planned "systematic approach" is required rather than an "opportunistic approach" during apprenticeship.

The field of medical education in Korea has also grown quantitatively and qualitatively, in line with changes in global medical education, and lately, it has been focusing on transforming into a "capability-oriented curriculum." This trend implies that medical education in Korea has been standardized with a certain level of quantitative foundation for doctor training.

With the advent of the post-modern era, as we enter the Fourth Industrial Revolution, education must be developed in the direction of "rediscovering people's values and maximizing their ability to adapt to change" and "to learn abilities." If we summarize it in one word, it is "creative problem-solving ability." 
Table 1. The SPICES model of educational strategies

\begin{tabular}{ll}
\hline Innovative strategy & Traditional strategy \\
\hline $\begin{array}{l}\text { Student-centered teaching } \\
\text { Problem-based learning }\end{array}$ & Teacher-centered teaching \\
$\begin{array}{l}\text { Integrated/Inter-professional } \\
\text { curricula }\end{array}$ & $\begin{array}{l}\text { Information gathering learning } \\
\text { Discipline-based curricula }\end{array}$ \\
$\begin{array}{l}\text { Community-based learning } \\
\text { Electives with a core program }\end{array}$ & Hospital-based learning \\
Systematic/planned approach & $\begin{array}{c}\text { Aniform standard program } \\
\text { approach }\end{array}$ \\
\hline
\end{tabular}

In the medical field in particular, an emergency situation can develop suddenly and problem-solving ability to apply expertise in such situations without apprehension is one of the most important attributes of doctors. This problem-solving ability is based on standardized expertise and skillful learning, and creativity can be applied at the same time. Sang-Ho Baek's argument, "Education for performable physicians," to implement the 21st-century medical education flow [3] is a representative example of the early emphasis on the importance of creativity in solving problems in various situations.

In this context, the concepts related to creative competencies will be compared and organized to identify its importance in medical education.

\section{Definition and properties of creativity}

The etymology of creativity originated in ancient Greece, and its definitions are so diverse that discussions continue to this day. Torrance [4], the master of creative education, expresses the confusion of creative justice by saying: "The debate over the definition of creativity continues over the last century, but nothing can define it completely...... The definition of creativity will go on constantly, and because of this imperfection, we will know more about creativity."

Although the etymology of creativity began in ancient Greece, for a long time "create" was regarded as the realm of God, not the human realm. However, with the transition to modern society, creativity has been extended to the human realm, and creativity and creative education discussed in modern education have developed along with the "scientific education of education" of the 20th century modern education. In 1950, Guilford's inaugural address to the American Psychological Association focused on creative education [5], and in the backdrop of the 1957 "Sputnik shock," it brought a new topic of creativity. This triggered vast research and definitions on the issue.

In particular, Rhodes [6], who analyzed the work of many scholars on creativity, rather than defining creativity as a single concept, argued that people, processes, environments, and products overlap each other. It is more productive to define it as working. To summarize the subject of creativity according to the researcher's point of view (Fig. 1).

First, in terms of emphasis on personality, creativity can be defined as human thinking ability and explained as 'spreading thinking' or 'divergent thinking.' Guilford [7], a representative scholar with an emphasis on people, defines creativity as divergent thinking, which involves creating something new. Since Guilford, this perspective has also defined creativity, focusing on the characteristics and dispositions of creative people.

Torrance [8], a representative scholar who emphasizes the creative process, says, "I chose a creative process with a focus on creative thinking." Creativity means a creative thinking process and a creative problem-solving process.

Another position that emphasizes creativity describes it as a psychological, social, and cultural environment that operates in the environment surrounding human beings. In other words, the environment is something that allows creativity to occur [9]. The "press" of the environment is a concept from Murray's personality theory [10], which means a significant environmental factor that influences behavioral decisions [9]. This view has recently evolved into a pluralistic view in which the four elements of creativity interact. Csikszentmihalyi [11] also defined creativity as a field of cultures, bringers of newness, and experts who recognize newness in the environment surrounding individual creative achievement.

From the perspective of emphasizing creative products, it focuses on creativity as a result of original thinking or creativity. Creative output includes both the visible and invisible aspects. [9]. In general, many people seem to use the "newness" and "value" of these outputs as the basis for judgment.

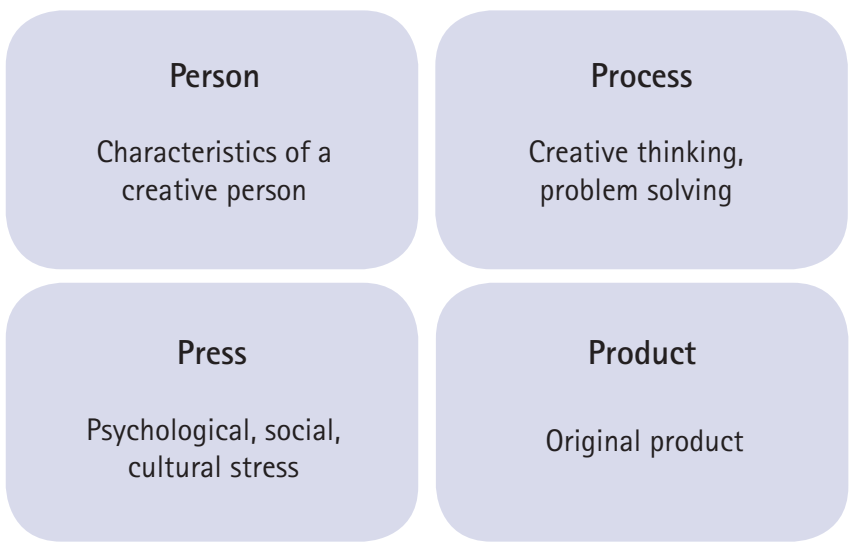

Fig. 1. The attributes of creativity. 
On the numerous definitions and scopes of creativity, Kaufman recently defined the concept of creativity in his book in 2016 [12], and further elucidated the "Four C Model" presented in 2009 [13]. This model is categorized into Big- $\mathrm{C}$ and little-c by adding mini-c and pro-c. Big-C suggests genius creativity, such as the likes of Mozart, Einstein, Armstrong, etc. While pro-c is not a genius, but a professional level of creativity, little-c refers to creativity expressed in day-to-day life, and mini-c refers to creative ideas inherent in everyone $[12,13]$.

The volume of studies on creativity in Korean education was insignificant until 1990, and its number has increased since the 2000s. However, in the study of creative education, conceptual studies on creativity have been scarce, and since the emergence of creativity and personality capabilities in the 2009 revised curriculum, the study of creative education commenced. Early creativity focuses on the concept of big creativity that develops something new, but recent research on creativity focuses on small creativity [14].

\section{Creativity and creation}

Similar vocabulary is commonly used in terms of "creative" and "creation." According to the Korean dictionary, creation is defined as "the first result of something that never existed," and creativity is defined as "new thoughts." Applying Rhodes' 4P concept mentioned earlier, creativity refers to a person's inclination to seek newness, the idea of pursuing a new perspective based on environmental factors, and the manifestation of such a will. Creation, on the other hand, places a greater emphasis on the end result or output of all these activities, and creation is considered an outcome of creativity. Kaufman's "Four C Model" also indicates that you can start with creativity and go on to creation. In order to resolve the confusion caused by the mixed use of the terms "creative" and "creation," they can be classified into the opinions and etymologies of scholars as follows (Fig. 2).

Creativity means to "create something out of nothing" or create something new from nothing. In Greek, there is a poiein, which means make, and is applied to poiethes, and only the poet is recognized as the maker of something. Conversely, in the Roman period, "crere," "creating" in addition to "facere" appeared, which implied "creatio ex nihiro" until the Middle Ages. By the 19th century, it was limited to the arts field and applied to poets and artists [15].

Creativity has since been defined to suggest that artists create something new, mainly in art-related activities. Creation is thus used to highlight the process and results of creating something in the absence of experts in the field.

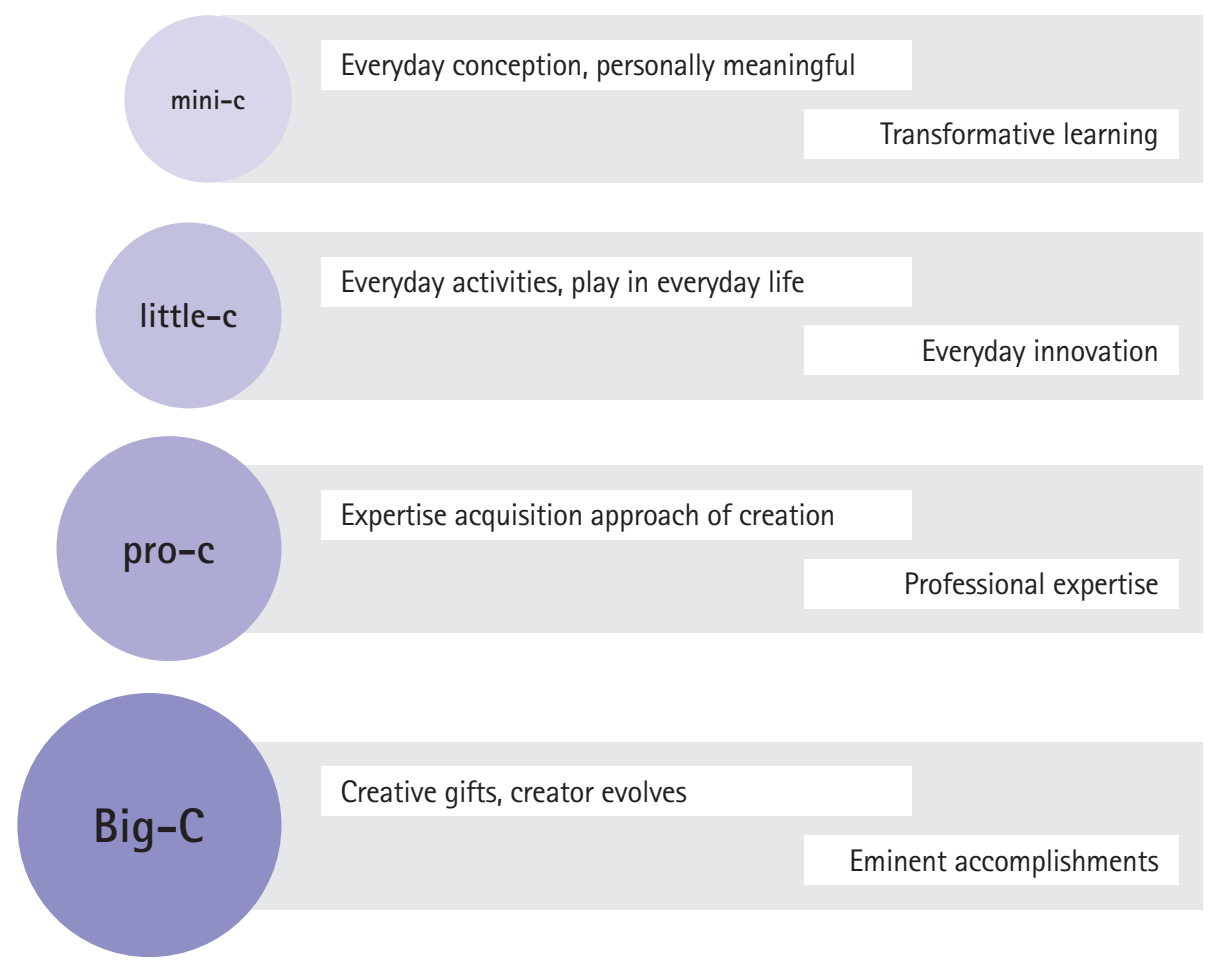

Fig. 2. The Four C Model of creation. 


\section{The importance of creativity}

Creativity is recognized as a norm in education, and it is a concept that is appropriate not only for education but also for all academic fields and human activities such as literature, art, science and technology [16]. Specifically, activities that are not socially normative or inappropriate are not considered creative. There are some misconceptions about creativity that remind us of new, extraordinary, unusual, and imaginative words [17]. (1) Something magical with only a few great geniuses. (2) Other unusual behavior, unconditional backlash. (3) Mental illness, associated with madness (ex. Gogh's ear cut). (4) Necessary only for persons with special positions in specific departments.

Creativity is based on a high intellectual ability, original thinking, independent judgment, and open thinking. A five-year-old who is not aware of social knowledge and norms depicts a square cow, a neckless mom, and a dad [1]. Knowing the old, adding the new, and having a morally reasonable good value is creativity. It is not known that a child who knows nothing draws a square-necked cow, not so creative, and unrestricted illusions and deviations are not called creativity [18]. On the contrary, children's expressions are considered to be of value only if they fit the established standards, adequacy, truth, and moral right [19]. Creativity is therefore basically an integrated capacity that adds new, good value in addition to standardized knowledge. Elements that define creativity are shown in Fig. 3.

One of the most important aspects of creative education in tertiary institutions is the full acquisition of standardized knowledge in the field of study. For example, when playing a piece of music, when the musician understands the song, memorizes the lyrics, uses the instrument skillfully, and has sufficient practice, he/she can make his/her own new interpretation of the piece. If you play an entirely new piece outside the scope of the song, it can be de-

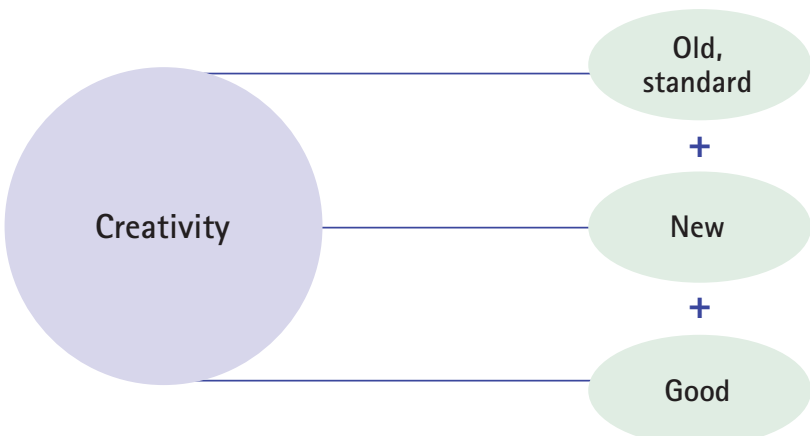

Fig. 3. Elements defining creativity. Creativity is therefore basically an integrated capacity that adds new, good value in addition to standardized knowledge. fined as an activity beyond creativity. Creativity is therefore not limited to any particular field of study but is a factor that must be pursued in all disciplines, beginning with day-to-day life.

\section{Medical education and creativity in Korea}

Since Korea's medical education has witnessed a significant growth since the 1990s, it has been striving for qualitative growth by reflecting changes in the medical environment and social needs. In recent years, with the introduction of competency-based and outcome-based curricula, attempts for qualitative growth have become more active, especially with the Korean Institute of Medical Education and Evaluation (KIMEE). Starting this year, medical schools adopted the new "Accreditation Standards of KIMEE 2019" (ASK2019) with the introduction of the World Federation for Medical Education's basic medical education evaluation criteria. The key to this new assessment standard is the shift from traditional quantitative assessments to qualitative assessments that emphasize university autonomy. The necessary and sufficient requirement for a qualitative assessment is the fulfillment of a quantification. The launch of qualitative evaluation through ASK2019 also presupposes that medical education in Korea has already met a certain standardization and quantitative level.

Therefore, it is time to be creative in the field of medical education. First of all, creative individuality needs to work at the university level. Rather than countering the entire medical education flow or creating an entirely new form, it should reflect the changes in individual schools and communities on a standardized basis to form a unique culture of the university. However, it is difficult to accept the demand for new changes in medical education as another process of uniformity.

Instead of eliminating the existing standards, creativity should combine new educational goals and ideas with old values, especially in the field of medical education.

In modern times, the pattern of disease has changed, with new symptoms and diseases emerging, and it has become common to treat patients of various nationalities. Therefore, medical education should once again verify the basics and progress of education that reflects the diversity of the community and students, and at the same time develop the ability of graduates to properly solve problems in various situations in the medical field. Not surprisingly, it is not a threat to the medical field, but it is only natural to have standardized basic knowledge.

It is not possible to respond to the fast-changing modern medical field with average standardized capacity. In addition, human capacity is multidimensional, and an educational environment in 
which one can fully experience and be sure of the ability to be used in different contexts is important. While the primary objective of medical students is to become doctors, ultimately every student may have a different goal. Therefore, in order to realize student-centric medical education, a curriculum that takes into consideration changing times and students' individual competencies should be prepared.

\section{Conclusion}

There are also concerns that medical education should be excluded from creative capacity, as the various definitions of creativity seem to involve the risk of considering doctors as creative. But creativity does not just mean something completely new, something completely special, as discussed earlier. Creativity is an ability that can be exercised when there is sufficient expertise in the field of study.

Creative capacity is defined as the ability of a doctor with sufficient standardized knowledge and competence to adapt to a situation based on basic expertise. This is the reason why creative capacity should be viewed anew in the field of medical education. We must go one step further for new growth.

\section{Acknowledgments}

\section{Conflicts of interest}

No potential conflict of interest relevant to this article was reported.

\section{Author contributions}

Conceptualization, data curation, formal analysis, project administration, supervision, visualization, writing-original draft, writing-review \& editing: YHL, YK.

\section{ORCID}

Yura Kim, https://orcid.org/0000-0001-5864-267X

Young Hwan Lee, https://orcid.org/0000-0001-8377-5802

\section{References}

1. Lee YH. Reflections and tasks on our medical education. Healthc Policy Forum 2019; 17(2):45-50.
2. Harden RM, Sowden S, Dunn WR. Educational strategies in curriculum development: the SPICES model. Med Educ 1984;18:284-97.

3. Baek SH. Future of medical education. Korean Med Educ Rev 2008; 10:1-8.

4. Torrance EP. The millennium: a time for looking forward and looking backward. Korean J Think Probl Solving 2000;19:519.

5. Guilford JP. Creativity. Am Psychol 1950;5:444-54.

6. Rhodes M. An analysis of creativity. Phi Delta Kappan 1961;42:305-10.

7. Guilford JP. The nature of human intelligence. New York: McGraw-Hill; 1967.

8. Torrance EP. Why fly? A philosophy of creativity. Norwood (NJ): Ablex; 1995.

9. Kim YC. Theory and development of creativity. Seoul (KR): Education Science Publishers; 2010.

10. Murray HA. Explorations in personality: a clinical and experimental study of fifty men of college age. Oxford (UK): Oxford University Press; 1938.

11. Csikszentmihalyi M. Creativity: flow and the psychology of discovery and invention. New York: HarperCollins Publishers; 1996.

12. Kaufman JC. Creativity 101. 2nd ed. New York: Springer Publishing Company; 2016.

13. Kaufman JC, Beghetto RA. Beyond big and little: the Four C Model of creativity. Rev Gen Psychol 2009;13:1-12.

14. Cho YS, Jeong JE. An analytical study on studies of creativity education in Korea: focusing on categories and levels of creativity.J Gift/Talent Educ 2012;22:333-52.

15. Park YT. Star of creativity. Seoul (KR): Hakjisa; 2002.

16. Jeong HP. Introduction to new education. Seoul (KR): Education Science Publishers; 2002.

17. Kim YC. Creativity: theory and education of potential. Seoul (KR): Yunsung Publishers; 2017.

18. Lytton H. Creative and education. London: Routledge \& Kegan Paul; 1971.

19. Barrow R. Plato and education. London: Routledge \& Kegan Paul; 1976. 